\title{
Lateral-Torsional Coupling Characteristics of a Two-Stage Planetary Gear Rotor System
}

\author{
Zhipeng Wang, Yunbo Yuan $(\mathbb{D}$, Zhiyong Wang $(\mathbb{D}$, Wei Liu $(\mathbb{D}$, \\ Yibin Guo $\mathbb{D}$, and Donghua Wang $\mathbb{D}$ \\ College of Power and Energy Engineering, Harbin Engineering University, Harbin, Heilongjiang Province, China \\ Correspondence should be addressed to Yunbo Yuan; yuanyunbo163@163.com and Donghua Wang; hitwdh@163.com
}

Received 23 January 2018; Revised 10 April 2018; Accepted 17 April 2018; Published 31 May 2018

Academic Editor: Emiliano Mucchi

Copyright (c) 2018 Zhipeng Wang et al. This is an open access article distributed under the Creative Commons Attribution License, which permits unrestricted use, distribution, and reproduction in any medium, provided the original work is properly cited.

\begin{abstract}
Planetary gears are one part of the whole transmission chain, and the dynamics and vibration characteristics of them are strongly coupled with external rotors. In this paper, to demonstrate the interaction between multistage planetary gears and external rotors as well as investigate the lateral-torsional coupling characteristics of them, a coupling model of a two-stage planetary gear rotor system is proposed. In such a model, the two-stage planetary gear subsystem is established as a lumped-parameter model and the external rotor subsystem is established as a finite element model. The vibration mode distribution properties and lateral-torsional coupling characteristics are both analyzed by modal strain energy. Three different conditions are considered: uncoupled, partially coupled, and fully coupled. The results indicate that the coupling among multiple subsystems and the lateral-torsional coupling mainly exist in the low-mode region. Natural frequencies dominated by the two-stage planetary gear subsystem are sensitive to coupled conditions, whereas natural frequencies dominated by the input rotor subsystem are remarkably insensitive to coupled conditions. Furthermore, the natural frequency of the first torsional mode can be obtained only in the fully coupled condition. Experiments are implemented to obtain natural frequencies, and the experiment results validate the numerical results.
\end{abstract}

\section{Introduction}

In the fields of helicopter, marine, automotive, and wind power, variable-speed devices with high power density, heavy carrying capacity, high torque-to-weight ratio, and efficiency are in demand. Compared with parallel-axis gears and singlestage planetary gears, multistage planetary gears are capable of transmitting the same amount of power with smaller volume and lighter weight, which makes them an important way of compact transmission [1]. Despite their benefits, multistage planetary gears often have more complex noise and vibration problems than single-stage planetary gears [2].

The mathematical model and vibration mode properties of simple, single-stage planetary gears have been studied extensively. Kahraman [3] derived a 2D planar lumpedparameter dynamic model, and he studied the vibration mode properties. Lin and Parker [4] analyzed the free vibration properties under the coordinates relative to the rotating carrier basis. Three types of modes were defined: translational, rotational, and planet modes. Cooley and Parker [5] showed that the single-mode vibration of spur planetary gear has well-defined geometry and frequency content due to its vibration mode structure. Lin and Parker [6] investigated the vibration of planetary gears with unequally spaced planet configurations. The planet modes were proved to be independent of planet spacing form, while the translational and rotational modes were considerably coupled and lost their distinct structure.

For multistage planetary gears, Kahraman [2] studied the vibration characteristics with different configurations and speed ratios using a purely rotational model. Guo and Parker [7] derived a purely rotational model of compound planetary gears to investigate the rotational vibration mode properties. They showed that there are exactly two vibration mode types, called overall modes and planet modes. Zhang et al. [8] presented a translational-rotational dynamic model of a twostage closed-form planetary gear to investigate the vibration 
characteristics. It was found that the coupling-twist stiffness only had a significant impact on translational modes while the coupling-translational stiffness only affected rotational modes.

However, most of the relative published papers are about planetary gears themselves and few researches on planetary gears and their external rotors have been found. Vibration mode properties of single-stage planetary gears and their external rotors were investigated by August and Kasuba [9] and Saada and Velex [10]. But there are very few literatures handling vibration mode properties of multistage planetary gears and their external rotors. Additionally, it is essential to develop a coupling mathematical model when the rigidity of external rotors is so large that input and output units have significant influence on multistage planetary gears. Through this way, one can get a more correct and more reliable vibration characteristics of multistage planetary gears.

Accordingly, the first objective of the present study is to develop a coupling mathematical model of multistage planetary gears and their external rotors; such a model takes translational and rotational degrees of freedom into account simultaneously. Then the coupling interaction between multistage planetary gear subsystem and external rotor subsystem will be investigated. A convenient and easy method to demonstrate the lateral-torsional coupling characteristics of vibration modes will be provided, since it is not easy to make mode shapes of complex systems readable.

In this paper, a lateral-torsional coupling mathematical model is proposed to investigate the free vibration characteristics of a two-stage planetary gear rotor system (the simplest form of the multistage planetary gear rotor system); three different coupling conditions between each two adjacent subsystems are considered in such a model. However, the same methodology can be applied to other forms of multistage planetary gear rotor system, such as three-stage and fourstage planetary gear rotor system. Furthermore, the modal strain energy (MSE) method is used to investigate the lateraltorsional coupling characteristics of vibration modes, and the relative deviation of natural frequencies dominated by the two-stage planetary gear subsystem. Finally, spinning test and modal test are implemented on a test rig, and Harmonic Response Analysis and Experimental Modal Analysis are performed in order to compare the experimental natural frequencies with the numerical results.

\section{Coupled Modelling and Equations of Motion}

In this paper, the research subject is shown in Figure 1, a two-stage planetary gear rotor system. The gear rotor system consists of a drive motor, a planetary gearbox, a load motor, input and output shafts, three couplings, two tilting pad bearings, and a balancing disk. The planetary gearbox is a two-stage reducer.

As shown in Figure 2, the two-stage planetary gear is connected in series by two simple, single-stage planetary gears with standstill ring gears. Its input unit is the sun gear of the first-stage, and its output unit is the carrier of the secondstage. The carrier of the first-stage and the sun gear of the second-stage are connected together by an involute profile inner spline.

2.1. Single-Stage Planetary Gear Dynamic Model. The 2D planar lumped-parameter dynamic model of simple, single-stage planetary gears is represented in Figure 3. Two translational and one rotational degrees are attributed to every central component. In total, the model has $9+3 N$ ( $N$ is the number of planets) degrees of freedom. The absolute coordinate $O X Y$ is established in the center of the sun gear, and the rotating coordinates $O x_{i} y_{i}$ are fixed and rotating with the carrier. The axis $x_{i},(i=s, c, r)$ is directed toward the equilibrium position of planet 1 . Translational coordinates $x_{n}$ and $y_{n}$ fixed to planet $n$ are radial and tangential coordinates, respectively.

Differing from the literature [4], the rotational coordinates are defined to be $\theta_{j},(j=s, c, r, 1,2, \ldots, n)$ rather than $u_{j}=r_{j} \theta_{j}$, for the sake of being more convenient to the following study. Hence, the governing equations for simple, single-stage planetary gears in matrix form are

$$
\begin{aligned}
\mathbf{M}_{g} \ddot{\mathbf{q}}_{g}+\omega_{c} \mathbf{J}_{g} \dot{\mathbf{q}}_{g}+\left[\mathbf{K}_{b}+\mathbf{K}_{e}(t)-\omega_{c}^{2} \mathbf{K}_{\omega}\right] \mathbf{q}_{g} & =\mathbf{T}+\mathbf{F}(t) \\
\mathbf{q}_{g} & =\left[\begin{array}{llllllllllllllllllll}
x_{s} & y_{s} & \theta_{s} & x_{r} & y_{r} & \theta_{r} & x_{1} & y_{1} & \theta_{1} & \ldots & x_{n} & y_{n} & \theta_{n} & x_{c} & y_{c} & \theta_{c}
\end{array}\right]^{T},
\end{aligned}
$$

where $\mathbf{M}_{g}, \mathbf{J}_{g}, \mathbf{K}_{b}, \mathbf{K}_{e}(t), \mathbf{K}_{\omega}$ are the mass, gyroscopic, elastic support stiffness, tooth mesh stiffness, and centrifugal stiffness matrices, respectively. $\mathbf{T}$ is the vector of applied external forces and torques, and $\mathbf{F}(t)$ represents the static transmission error excitation vector.

For further simplicity, it defines that $\mathbf{K}_{g}=\mathbf{K}_{b}+\mathbf{K}_{e}(t)-$ $\omega_{c}^{2} \mathbf{K}_{\omega}, \mathbf{Q}_{g}=\mathbf{T}+\mathbf{F}(t)$. Therefore, (1a) can be rewritten as follows:

$$
\mathbf{M}_{g} \ddot{\mathbf{q}}_{g}+\omega_{c} \mathbf{J}_{g} \dot{\mathbf{q}}_{g}+\mathbf{K}_{g} \mathbf{q}_{g}=\mathbf{Q}_{g}
$$

2.2. Coupled Modelling of Two-Stage Planetary Gear. For the two-stage planetary gear in this paper, the carrier of firststage is connected with the sun gear of second-stage by an involute profile inner spline. The boundary conditions of these two components differ from those of simple, singlestage planetary gears, which is shown in Figure 4.

Define the radial coupling stiffness as $k_{g x}, k_{g y}$ and the torsional coupling stiffness as $k_{g \theta}$; then equations of motion of the carrier of first-stage and the sun gear of second-stage can be derived as (3) and (4), respectively. 


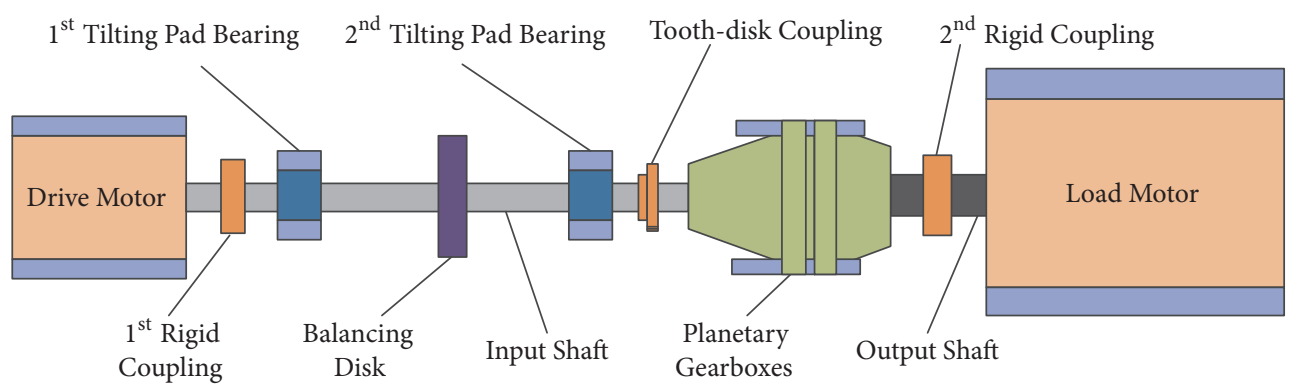

FIGURE 1: Schematic of the two-stage planetary gear rotor system.

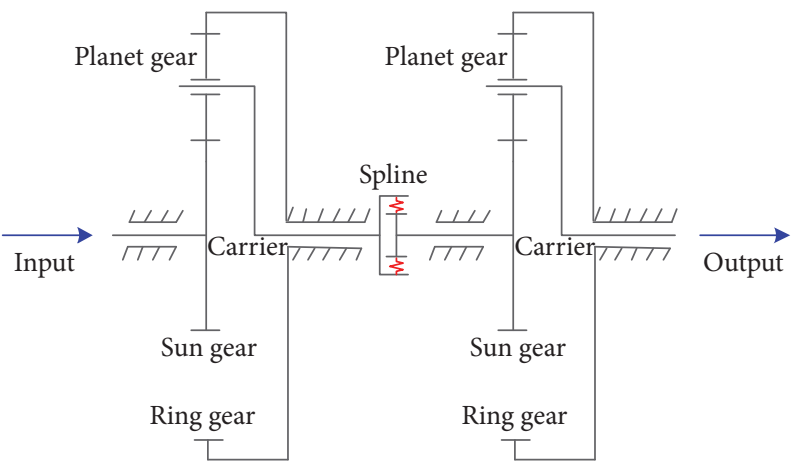

FIGURE 2: Scheme of two-stage planetary gear with standstill ring gears.

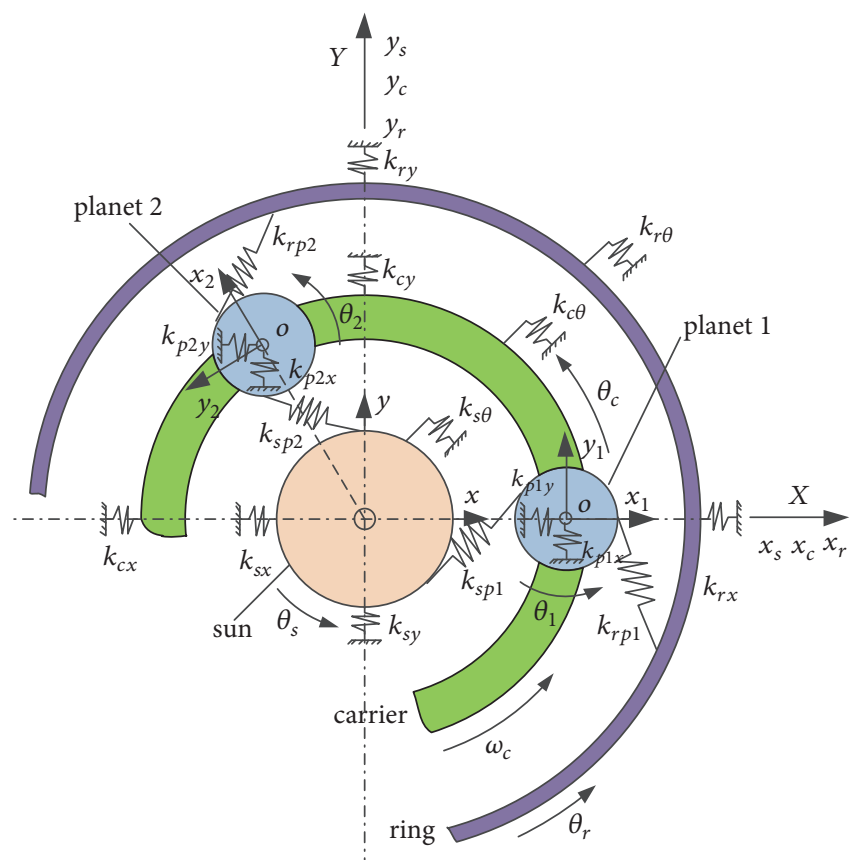

FIGURE 3: Lumped-parameter planetary gear model and system coordinates.

$$
\begin{array}{lr}
m_{c}^{\mathrm{I}}\left(\ddot{x}_{c}^{\mathrm{I}}-2 \omega_{c}^{\mathrm{I}} \dot{y}_{c}^{\mathrm{I}}-\left(\omega_{c}^{\mathrm{I}}\right)^{2} x_{c}^{\mathrm{I}}\right)+\sum_{n=1}^{N} k_{p n}^{\mathrm{I}} \delta_{c n x}^{\mathrm{I}}+k_{c x}^{\mathrm{I}} x_{c}^{\mathrm{I}} & +k_{g y}\left(y_{c}^{\mathrm{I}}-y_{s}^{\mathrm{II}}\right)=0 \\
+k_{g x}\left(x_{c}^{\mathrm{I}}-x_{s}^{\mathrm{II}}\right)=0 & I_{c}^{\mathrm{I}} \ddot{\theta}_{c}^{\mathrm{I}}+\sum_{n=1}^{N} k_{p n}^{\mathrm{I}} \delta_{c n \theta}^{\mathrm{I}} r_{c}^{\mathrm{I}}+k_{c \theta}^{\mathrm{I}}(r) \\
m_{c}^{\mathrm{I}}\left(\ddot{y}_{c}^{\mathrm{I}}+2 \omega_{c}^{\mathrm{I}} \dot{x}_{c}^{\mathrm{I}}-\left(\omega_{c}^{\mathrm{I}}\right)^{2} y_{c}^{\mathrm{I}}\right)+\sum_{n=1}^{N} k_{p n}^{\mathrm{I}} \delta_{c n y}^{\mathrm{I}}+k_{c y}^{\mathrm{I}} y_{c}^{\mathrm{I}} & +k_{g \theta} r_{c}^{\mathrm{I}}\left(r_{c}^{\mathrm{I}} \theta_{c}^{\mathrm{I}}-r_{s}^{\mathrm{II}} \theta_{s}^{\mathrm{II}}\right)
\end{array}
$$




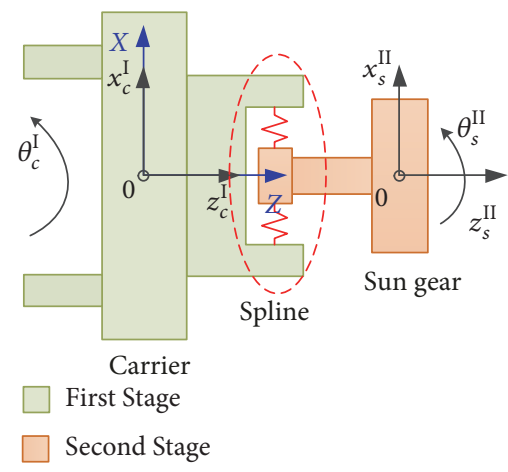

FIGURE 4: Schematic of the coupling relation of first-stage and second-stage.

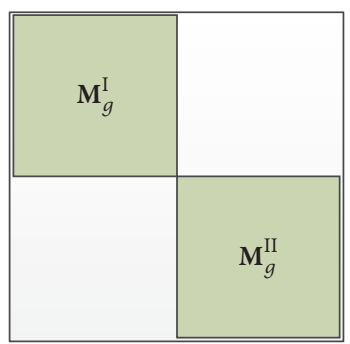

(a)

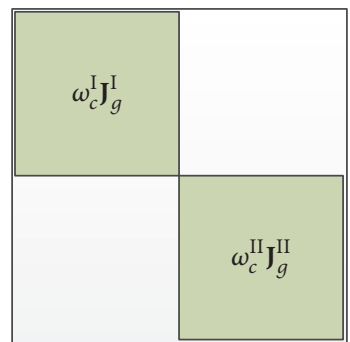

(b)

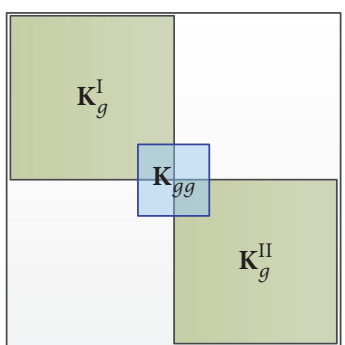

(c)

Figure 5: Assembly of the two-stage planetary gear system matrices: (a) the mass matrix, (b) the gyroscopic matrix, and (c) the stiffness matrix.

$$
\begin{aligned}
& m_{s}^{\mathrm{II}}\left(\ddot{x}_{s}^{\mathrm{II}}-2 \omega_{c}^{\mathrm{II}} \dot{y}_{s}^{\mathrm{II}}-\left(\omega_{c}^{\mathrm{II}}\right)^{2} x_{s}^{\mathrm{II}}\right)-\sum_{n=1}^{N} k_{s p n}^{\mathrm{II}} \delta_{s p n}^{\mathrm{II}} \sin \psi_{s n}^{\mathrm{II}} \\
& +k_{s x}^{\mathrm{II}} x_{s}^{\mathrm{II}}+k_{g x}\left(x_{s}^{\mathrm{II}}-x_{c}^{\mathrm{I}}\right)=0 \\
& m_{s}^{\mathrm{II}}\left(\ddot{y}_{s}^{\mathrm{II}}+2 \omega_{c}^{\mathrm{II}} \dot{x}_{s}^{\mathrm{II}}-\left(\omega_{c}^{\mathrm{II}}\right)^{2} y_{s}^{\mathrm{II}}\right)+\sum_{n=1}^{N} k_{s p n}^{\mathrm{II}} \delta_{s p n}^{\mathrm{II}} \cos \psi_{s n}^{\mathrm{II}} \\
& +k_{s y}^{\mathrm{II}} y_{s}^{\mathrm{II}}+k_{g y}\left(y_{s}^{\mathrm{II}}-y_{c}^{\mathrm{I}}\right)=0 \\
& I_{s}^{\mathrm{II}} \ddot{\theta}_{s}^{\mathrm{II}}+\sum_{n=1}^{N} k_{s p n}^{\mathrm{II}} \delta_{s p n}^{\mathrm{II}} r_{s}^{\mathrm{II}}+k_{s \theta}^{\mathrm{II}}\left(r_{s}^{\mathrm{II}}\right)^{2} \theta_{s}^{\mathrm{II}} \\
& +k_{g \theta} r_{s}^{\mathrm{II}}\left(r_{s}^{\mathrm{II}} \theta_{s}^{\mathrm{II}}-r_{c}^{\mathrm{I}} \theta_{c}^{\mathrm{I}}\right)=0
\end{aligned}
$$

Extracting the coupling elements from (3) and (4), the coupling stiffness submatrix for the first-stage and the second-stage planetary gears is given as follows:

$$
\begin{aligned}
& \mathbf{K}_{g g} \\
& \quad=\left[\begin{array}{cccccc}
k_{g x} & 0 & 0 & -k_{g x} & 0 & 0 \\
0 & k_{g y} & 0 & 0 & -k_{g y} & 0 \\
0 & 0 & k_{g \theta}\left(r_{c}^{\mathrm{I}}\right)^{2} & 0 & 0 & -k_{g \theta} r_{c}^{\mathrm{I}} r_{s}^{\mathrm{II}} \\
-k_{g x} & 0 & 0 & k_{g x} & 0 & 0 \\
0 & -k_{g y} & 0 & 0 & k_{g y} & 0 \\
0 & 0 & -k_{g \theta} r_{c}^{\mathrm{I}} r_{s}^{\mathrm{II}} & 0 & 0 & k_{g \theta}\left(r_{s}^{\mathrm{II}}\right)^{2}
\end{array}\right]
\end{aligned}
$$

Hence, the equations of motion of the two-stage planetary gear can be obtained as

$$
\mathbf{M}_{G}\left\{\ddot{\mathbf{q}}_{G}\right\}+\omega_{c} \mathbf{J}_{G}\left\{\dot{\mathbf{q}}_{G}\right\}+\mathbf{K}_{G}\left\{\mathbf{q}_{G}\right\}=\mathbf{Q}_{G},
$$

where $\mathbf{q}_{G}=\left\{\begin{array}{ll}\mathbf{q}_{g}^{\mathrm{I}} & \mathbf{q}_{g}^{\mathrm{II}}\end{array}\right\}^{T}$ is the vector of generalized displacements, and $\mathbf{Q}_{G}=\left\{\mathbf{Q}_{g}^{\mathrm{I}} \mathbf{Q}_{g}^{\mathrm{II}}\right\}^{T}$ is the vector of applied forces and torques. The assembly of the mass, gyroscopic, and stiffness matrices is illustrated in Figure 5.

2.3. Finite Element Model of External Rotor. The external rotor subsystem is analyzed by employing Timoshenko beam theory. A generalized displacement vector of each node can be defined with respect to the global coordinate system as $\left[x, y, \vartheta_{x}, \vartheta_{y}, \theta\right]^{T}$, where $x, y$ represent translational degrees, $\vartheta_{x}, \vartheta_{y}$ represent bending degrees, and $\theta$ represents rotational degree. For the sake of simplicity, all support bearings are supposed to be linear. Only the direct stiffness is considered and the damping effect is ignored.

Figure 6(a) shows a schematic of the input rotor subsystem and Figure 6(c) shows a schematic of the output rotor subsystem. The corresponding finite element models of these two subsystems are illustrated in Figures 6(b) and 6(d). For the input rotor subsystem, there are 39 nodes, 35 shaft elements, 6 disk elements, 5 bearing elements, and 3 coupling elements. Similarly, the output rotor subsystem is divided into 3 nodes, including 1 shaft element, 3 disk elements, 1 bearing element, and 2 coupling elements, which has a total of 15 degrees of freedom. 


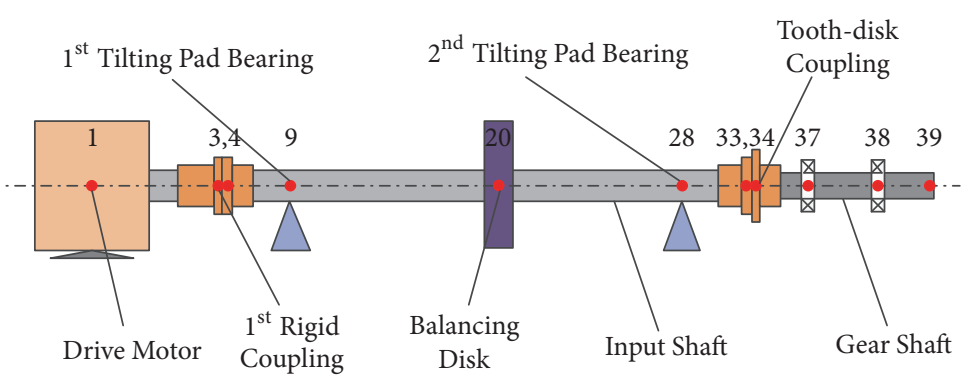

(a)

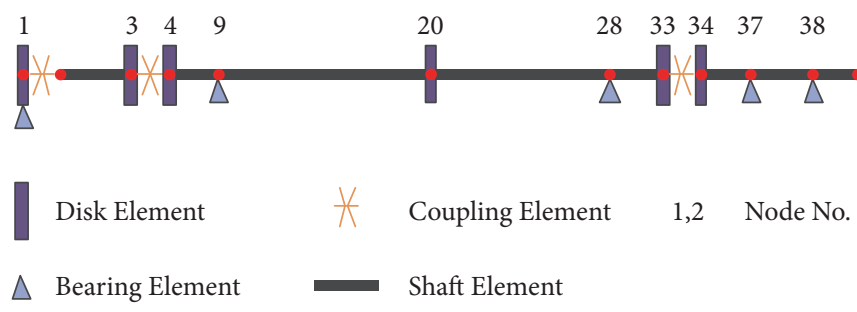

(b)

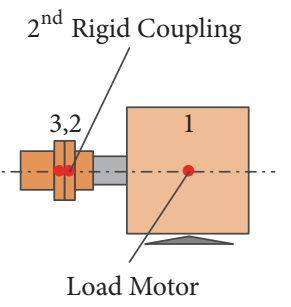

(c)
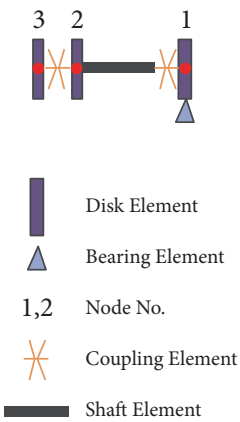

(d)

Figure 6: Model of external rotor subsystem: (a) schematic of input rotor subsystem, (b) finite element model of input rotor subsystem, (c) schematic of output rotor subsystem, and (d) finite element model of output rotor subsystem.

Equations of motion of the input rotor subsystem and the output rotor subsystem in matrix form are as follows:

$$
\begin{aligned}
\mathbf{M}_{\mathrm{IR}}\left\{\ddot{\mathbf{q}}_{\mathrm{IR}}\right\}+\mathbf{G}_{\mathrm{IR}}\left\{\dot{\mathbf{q}}_{\mathrm{IR}}\right\}+\mathbf{K}_{\mathrm{IR}}\left\{\mathbf{q}_{\mathrm{IR}}\right\} & =\mathbf{Q}_{\mathrm{IR}} \\
\mathbf{M}_{\mathrm{OR}}\left\{\ddot{\mathbf{q}}_{\mathrm{OR}}\right\}+\mathbf{G}_{\mathrm{OR}}\left\{\dot{\mathbf{q}}_{\mathrm{OR}}\right\}+\mathbf{K}_{\mathrm{OR}}\left\{\mathbf{q}_{\mathrm{OR}}\right\} & =\mathbf{Q}_{\mathrm{OR}},
\end{aligned}
$$

where $\mathbf{M}_{\mathrm{IR}}$ and $\mathbf{M}_{\mathrm{OR}}$ are the mass matrices, $\mathbf{G}_{\mathrm{IR}}$ and $\mathbf{G}_{\mathrm{OR}}$ are the gyroscopic matrices, and $\mathbf{K}_{\mathrm{IR}}$ and $\mathbf{K}_{\mathrm{OR}}$ are the stiffness matrices. The details of these matrices are given in [11].

\subsection{Coupled Modelling of Planetary Gear and External Rotor.} With the matrices of the two-stage planetary gear subsystem, the input rotor subsystem, and the output rotor subsystem available, the governing equations of the two-stage planetary gear rotor system are constructed systematically as

$$
\mathbf{M}\{\ddot{\mathbf{q}}\}+\mathbf{G}\{\dot{\mathbf{q}}\}+\mathbf{K}\{\mathbf{q}\}=\mathbf{Q}
$$

The generalized displacement vector, the mass matrix, the gyroscopic matrix, and the applied force vector are given in (8b)-(8e), respectively.

$$
\begin{aligned}
& \mathbf{q}=\left\{\begin{array}{lll}
\mathbf{q}_{\mathrm{IR}} & \mathbf{q}_{G} & \mathbf{q}_{\mathrm{OR}}
\end{array}\right\}^{T} \\
& \mathbf{M}=\operatorname{diag}\left\{\mathbf{M}_{\mathrm{IR}}, \mathbf{M}_{G}, \mathbf{M}_{\mathrm{OR}}\right\} \\
& \mathbf{G}=\omega \mathbf{J}=\operatorname{diag}\left\{\omega_{\mathrm{IR}} \mathbf{J}_{\mathrm{IR}}, \omega_{\mathrm{G}} \mathbf{J}_{\mathrm{G}}, \omega_{\mathrm{OR}} \mathbf{J}_{\mathrm{OR}}\right\} \\
& \mathbf{Q}=\left\{\begin{array}{lll}
\mathbf{Q}_{\mathrm{IR}} & \mathbf{Q}_{\mathrm{G}} & \mathbf{Q}_{\mathrm{OR}}
\end{array}\right\}^{T},
\end{aligned}
$$

where subscripts IR, $G$, and OR denote the input rotor, twostage planetary gear, and output rotor subsystem, respectively.

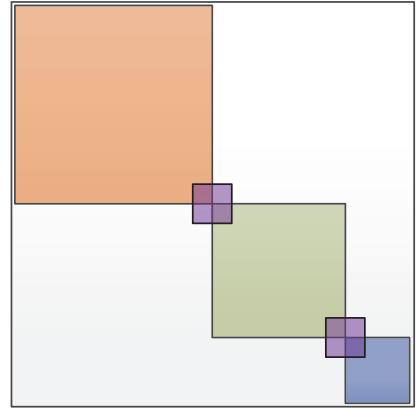

$$
\begin{aligned}
& \text { Input Rotor Submatrix } \\
& \text { Planetary Gear Submatrix } \\
& \text { Output Rotor Submatrix } \\
& \text { Coupling Submatrix }
\end{aligned}
$$

FIGURE 7: Assembly of the overall stiffness matrix of the gear rotor system.

The stiffness matrix $\mathbf{K}$ in (8a), the overall stiffness matrix, is demonstrated in Figure 7. It is assembled by the input rotor block submatrix, the planetary gear block submatrix, the output rotor block submatrix, and three coupling submatrices.

\section{Natural Frequencies and Vibration Modes}

3.1. Eigenvalue Problem and System Parameters. To determine the natural frequencies, the linear, time-invariant representation is considered. All mesh stiffness is considered to be constant and equal to the corresponding average stiffness, which can be calculated as in [12]. Assuming the system 


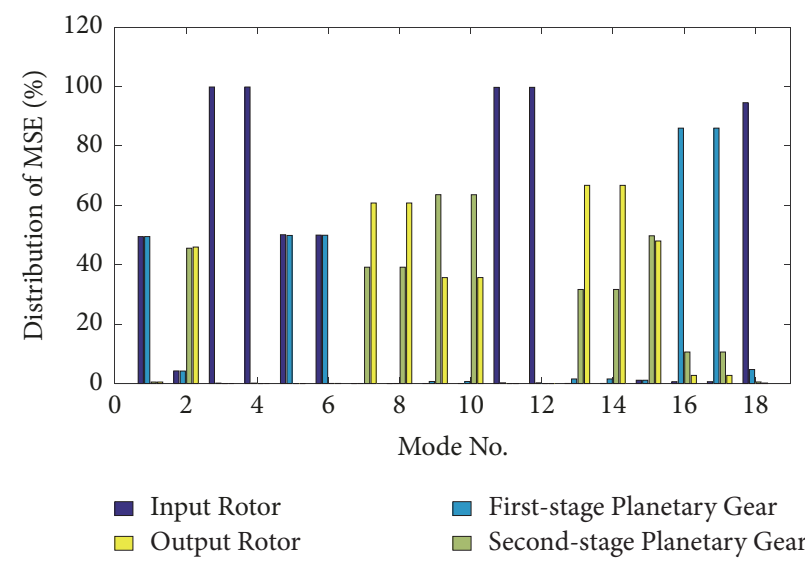

(a)

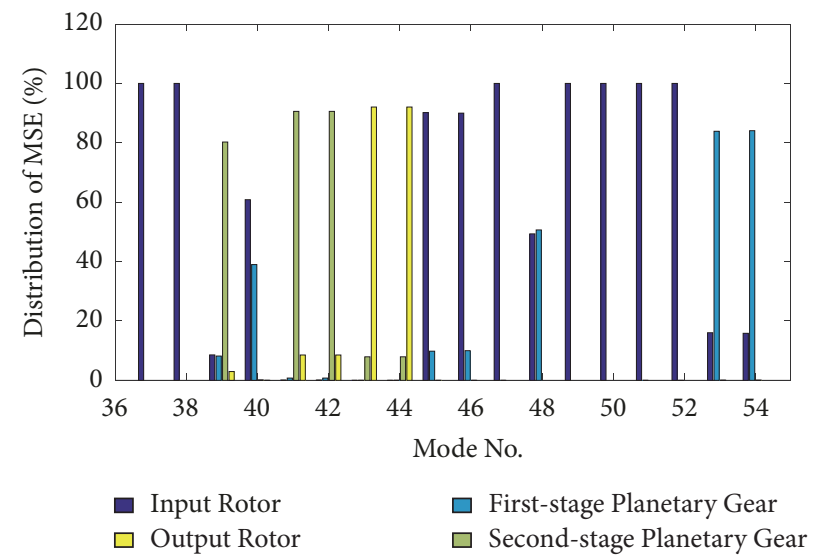

(c)

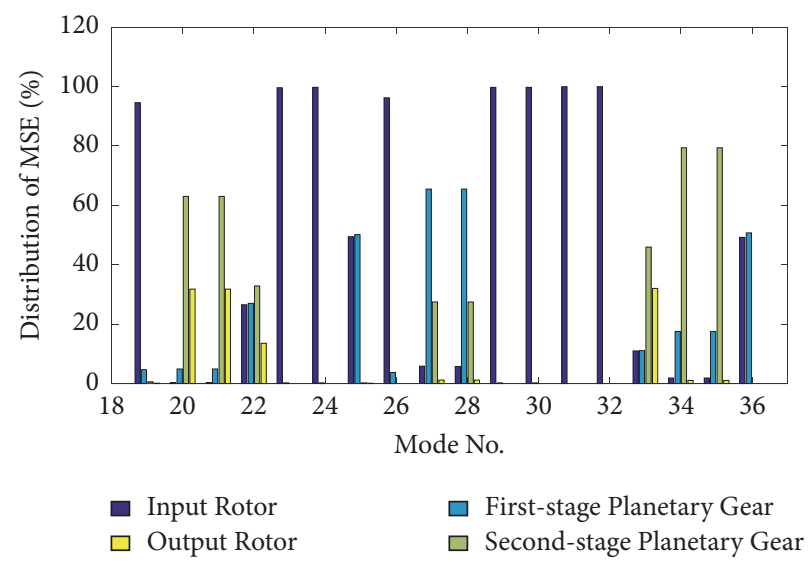

(b)

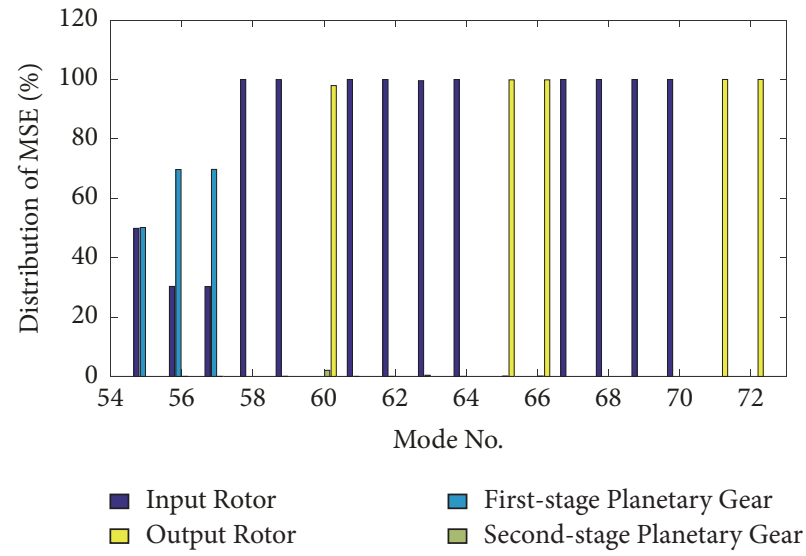

(d)

Figure 8: MSE distribution of each mode associated with each subsystem: (a) the first 18 modes, (b) the 19th 36th modes, (b) the 37th 54th modes, and (b) the 55th 72nd modes.

operates at lower speed, the gyroscopic and centrifugal terms can be neglected [4]. For such a special case, (8a) can be rewritten as

$$
\mathbf{M} \ddot{\mathbf{q}}+\left[\mathbf{K}_{b}+\overline{\mathbf{K}}_{e}\right] \mathbf{q}=0
$$

The associated eigenvalue problem derived from $\mathbf{q}(t)=$ $\phi \cos \omega t$ is

$$
\omega_{i}^{2} \mathbf{M} \phi_{i}=\left(\mathbf{K}_{b}+\overline{\mathbf{K}}_{e}\right) \phi_{i},
$$

where $\omega_{i}$ and $\phi_{i}$ are the natural frequencies and the corresponding vibration modes, respectively.

For the numerical study, essential parameters of the twostage planetary gear subsystem are given in Tables 1(a)-1(b). The stiffness of tilting pad bearings and rigid couplings of the external rotor subsystem are listed in Table 2.

With the parameters given in Tables 1 and 2, the natural frequencies of this two-stage planetary gear rotor system can be determined, and the first 72 natural frequencies are listed in Table 3.

3.2. Modal Strain Energy of Vibration Modes. In virtue of the complexity of the system studied in this paper, vibration modes cannot be expressed in figure intuitively. For the sake of convenience, MSE method is used to weigh which subsystem is the most dominant one in the entire system for each vibration mode. MSE of the entire system is given as

$$
\mathbf{U}_{\text {total }}=\frac{1}{2} \mathbf{q}^{T} \mathbf{K} \mathbf{q}=\mathbf{U}_{\mathrm{IR}}+\mathbf{U}_{g}^{\mathrm{I}}+\mathbf{U}_{g}^{\mathrm{II}}+\mathbf{U}_{\mathrm{OR}},
$$

where $\mathbf{U}_{\mathrm{IR}}, \mathbf{U}_{g}^{\mathrm{I}}, \mathbf{U}_{g}^{\mathrm{II}}, \mathbf{U}_{\mathrm{OR}}$ are MSE of the input rotor, first-stage planetary gear, second-stage planetary gear, and output rotor subsystem, respectively.

Furthermore, in order to investigate the lateral-torsional coupling characteristics of each vibration mode clearly, the other form of $\mathbf{U}_{\text {total }}$ is expressed as

$$
\mathbf{U}_{\text {total }}=\frac{1}{2} \mathbf{q}^{T} \mathbf{K} \mathbf{q}=\mathbf{U}_{\text {lateral }}+\mathbf{U}_{\text {torsional }}+\mathbf{U}_{\text {coupling }}
$$

where $\mathbf{U}_{\text {lateral }}, \mathbf{U}_{\text {torsional, }}$, and $\mathbf{U}_{\text {coupling }}$ are MSE associated with the lateral, torsional, and lateral-torsional coupling vibration, respectively.

With definitions of MSE in (11) and (12), MSE of each subsystem are separately calculated; meanwhile, the MSE associated with the lateral, torsional, and lateral-torsional coupling modes are determined. MSE distribution of each mode associated with each subsystem is depicted in Figure 8. 
TABLE 1: Essential parameters of the two-stage planetary gear subsystem.

(a)

\begin{tabular}{lcccc}
\hline Stage & component & Mass $(\mathrm{kg})$ & Base radius $(\mathrm{m})$ & \\
\hline \multirow{3}{*}{ First-stage } & carrier & 8.346 & 0.064 & 0.0332 \\
& ring & 9.423 & 0.095 & 0.1525 \\
& sun & 0.790 & 0.024 & 0.0002 \\
& planet & 0.620 & 0.035 & 0.0007 \\
\hline \multirow{3}{*}{ Second-stage } & carrier & 30.000 & 0.086 & 0.1554 \\
& ring & 25.000 & 0.120 & 0.6780 \\
& sun & 3.765 & 0.041 & 0.0026 \\
& planet & 1.360 & 0.039 & 0.0017 \\
\hline
\end{tabular}

(b)

\begin{tabular}{lcccc}
\hline Stage & Pressure angle $\left(^{\circ}\right)$ & $\begin{array}{c}\text { Mesh stiffness } \\
(\mathrm{N} / \mathrm{m})\end{array}$ & $\begin{array}{c}\text { Bearing stiffness } \\
(\mathrm{N} / \mathrm{m})\end{array}$ & $\begin{array}{c}\text { Torsional Stiffness } \\
(\mathrm{N} \cdot \mathrm{m} / \mathrm{rad})\end{array}$ \\
\hline $\begin{array}{l}\text { First-stage } \\
\text { Second-stage }\end{array}$ & 20 & $k_{s p}^{\mathrm{I}}=k_{r p}^{\mathrm{I}}=2 \times 10^{9}$ & $k_{p}=k_{s}=k_{r}=10^{8}$ & $k_{r \theta}=10^{9}$ \\
$k_{s \theta}=k_{c \theta}=0$ & $k_{s p}^{\mathrm{II}}=k_{r p}^{\mathrm{II}}=3 \times 10^{9}$ & & \\
\hline
\end{tabular}

TABLE 2: Stiffness parameters of the external rotor subsystem.

\begin{tabular}{lccccc}
\hline & 1st tilting pad bearing & 2nd tilting pad bearing & 1st rigid coupling & Tooth-disk coupling & 2nd rigid coupling \\
\hline$k_{x x}(\mathrm{~N} / \mathrm{m})$ & $8.70 \mathrm{E}+08$ & $5.40 \mathrm{E}+08$ & $2.50 \mathrm{E}+08$ & $4.50 \mathrm{E}+08$ & $8.00 \mathrm{E}+08$ \\
$k_{y y}(\mathrm{~N} / \mathrm{m})$ & $9.00 \mathrm{E}+08$ & $5.80 \mathrm{E}+08$ & $2.50 \mathrm{E}+08$ & $4.80 \mathrm{E}+08$ & $8.00 \mathrm{E}+08$ \\
$k_{\theta}(\mathrm{N} \cdot \mathrm{m} / \mathrm{rad})$ & -- & -- & $1.90 \mathrm{E}+05$ & $1.70 \mathrm{E}+05$ & $2.22 \mathrm{E}+06$ \\
\hline
\end{tabular}

And MSE distribution of each mode associated with the lateral, torsional, and lateral-torsional coupling modes is illustrated in Figure 9.

In this paper, for the convenience of the following discussion, we arbitrarily define that the region containing the first one-quarter modes of a system is the low-mode region and the region containing the last three-quarters modes of a system is the high-mode region. Accordingly, the first 61st modes are in the low-mode region and those modes higher than 61st mode are in the high-mode region, since there are 246 modes in all of this two-stage planetary gear rotor system.

As shown in Figure 8, for the modes such as 2nd, 13th 22nd, and 27th, MSE is distributed among multiple subsystems. For the modes such as 1st, 5th 10th, and 25th, MSE is distributed mainly in two adjacent subsystems. However, for the modes such as 3rd, 4th, 11th, and 29th 32nd, MSE is only distributed in the input rotor subsystem and in the output rotor subsystem. Moreover, one can particularly notice that MSE mainly concentrates in one subsystem for the 61st mode as well as for the modes higher than 61st mode. The above phenomena indicate that the coupling modes among subsystems only exist in the low-mode region, whereas, in the high-mode region, the modes are uncoupling and independent modes of the external rotor subsystem.

As shown in Figure 9, for the modes such as 1st, 2nd, 5 th 10th, and 13th 22nd, MSE is stored in three components including the lateral vibration component, the torsional vibration component, and the lateral-torsional coupling component. For the modes such as 3rd, 4th, 11th, 12th, and 23rd, MSE is only stored in the lateral vibration component; it indicates that these modes are the lateral vibration modes. Conversely, for the modes such as 26th, 47th, and 60th, MSE is only stored in the torsional vibration component; it indicates that these modes are the torsional vibration modes. However, one can particularly notice that MSE is only stored in the lateral vibration component or in the torsional vibration component for the 58th mode as well as for the modes higher than 58th mode, with no coupling components existing. It can be concluded from Figure 9 that there is no coupling effect between the lateral and torsional vibration in the high-mode region.

Meanwhile, Figures 8 and 9 clearly indicate that those modes dominated by the external rotor subsystem in the high-mode region are particularly the lateral and torsional decoupling modes. A main reason for this phenomenon is that no interaction between lateral and torsional vibration is taken into consideration for the finite element model of the external rotor subsystem.

Figures 8 and 9 also show that the coupling modes among subsystems in the low-mode region are particularly the lateral-torsional coupling modes, such as the 7 th 10 th and the 20th 22nd modes. The mesh interactions of the sun-planet and the ring-planet gear pair contribute to the lateral vibration coupling with the torsional vibration. The interactions here are the torsional torque term contained in the lateral vibration equations, and, on the other hand, the torsional vibration equations contain the lateral force term as well. 


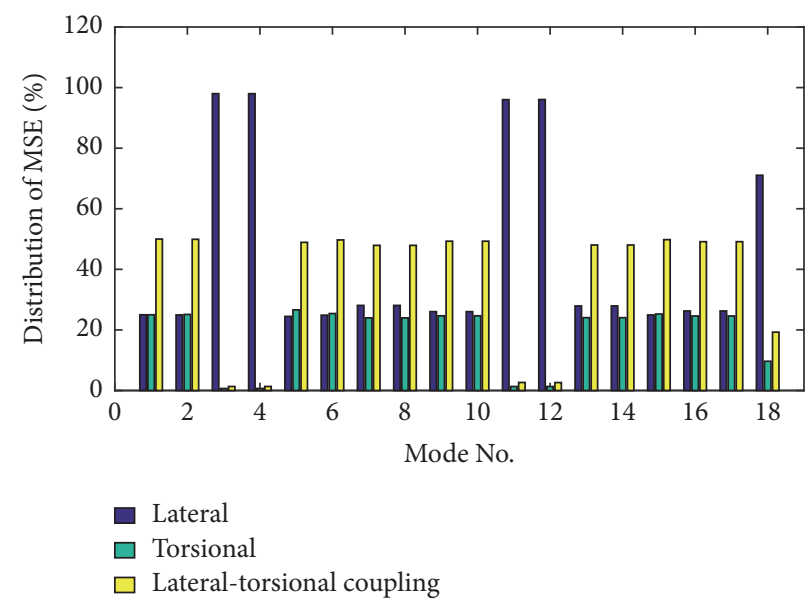

(a)

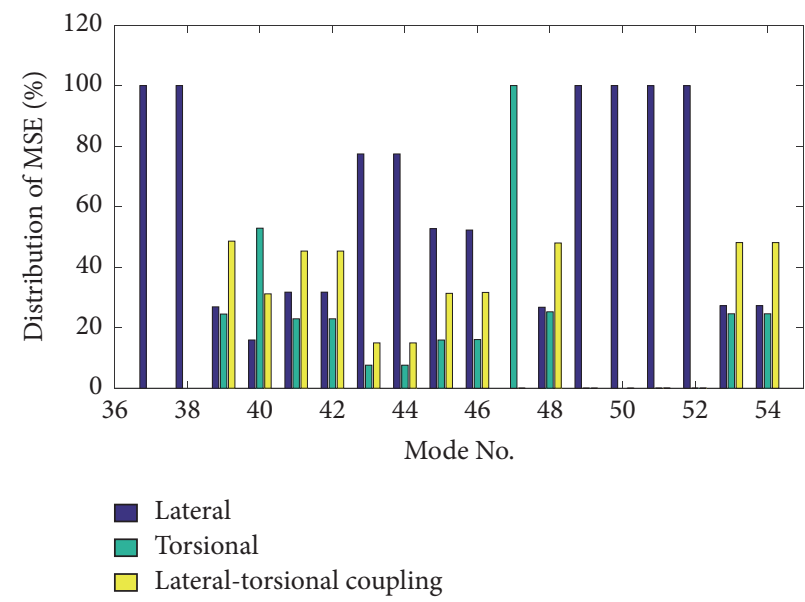

(c)

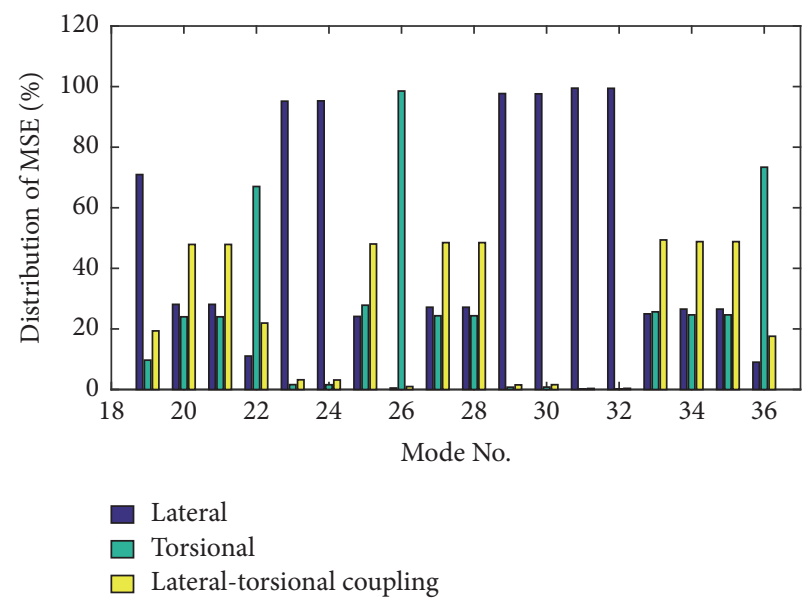

(b)

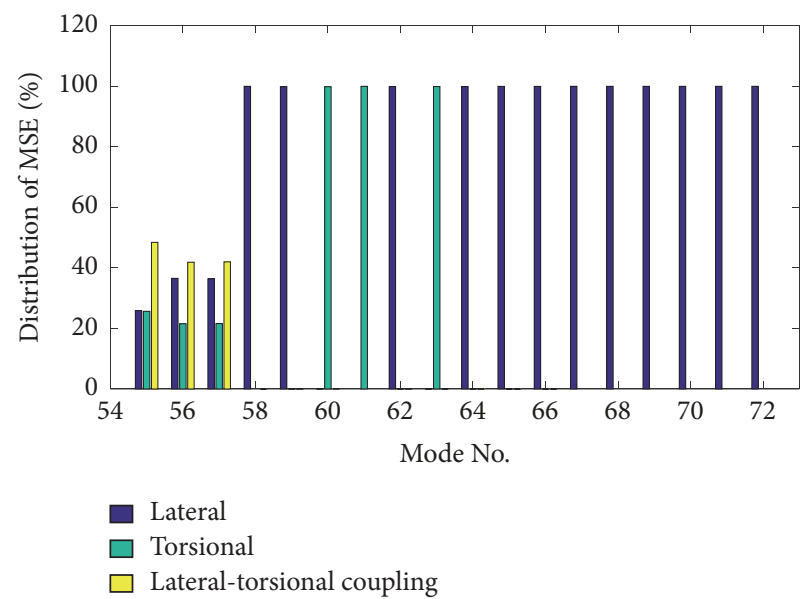

(d)

FIGURE 9: MSE distribution of each mode associated with the lateral, torsional, and lateral-torsional coupling modes: (a) the first 18 modes, (b) the 19th 36th modes, (c) the 37th 54th modes, and (d) the 55th 72nd modes.

3.3. Relative Deviation of Natural Frequency between Coupled and Uncoupled Conditions. In this section, the relative deviation of the natural frequencies dominated by the planetary gear subsystem and the input rotor subsystem is analyzed, respectively. Three different conditions are considered: (i) no coupling of each two adjacent subsystems is considered (uncoupled), (ii) only the coupling between the first-stage and the second-stage planetary gear is considered, without interaction between the two-stage planetary gear subsystem and the external rotor subsystem (partially coupled), and (iii) the coupling of each two adjacent subsystems is taken into account simultaneously, namely, the interaction between the input rotor subsystem and the first-stage planetary gear and the first-stage and the second-stage planetary gear, as well as the second-stage planetary gear and the output rotor subsystem being all considered simultaneously (fully coupled).

3.3.1. Natural Frequency Dominated by Two-Stage Planetary Gear. Herein, to select the natural frequencies dominated by the two-stage planetary gear subsystem under the above three conditions, MSE defined in (11) and (12) is separately calculated for each natural frequency. Then, the relative deviation of such natural frequencies is analyzed under partially coupled condition and under fully coupled condition relative to uncoupled condition, respectively.

The relative deviation of the natural frequencies dominated by the two-stage planetary gear subsystem is shown in Figure 10. However, two rigid-body modes for the firststage and the second-stage planetary gear under uncoupled condition are not included in Figure 10. The relative deviation of such two modes will be discussed later.

As indicated in Figure 10(a), for the 9th, 10th, and 48 th 57 th modes, the natural frequencies obtained under fully coupled condition have a significant increase compared with those obtained under uncoupled condition. However, these natural frequencies almost keep constant under partially coupled condition compared to those under uncoupled condition. Compared with uncoupled condition, the 16th, 17 th, 20th, 21st, 27th, and 28th natural frequencies have an increase of about $5 \%$ in partially coupled condition, and a more remarkable increase is found in fully coupled condition. 
TABLE 3: Natural frequencies of the two-stage planetary gear rotor system.

\begin{tabular}{|c|c|}
\hline Mode No. & Freq. $(\mathrm{Hz})$ \\
\hline 1 & 0 \\
\hline 2 & 56.6 \\
\hline 3 & 83.7 \\
\hline 4 & 83.7 \\
\hline 5 & 151.2 \\
\hline 6 & 248.5 \\
\hline 7 & 298.9 \\
\hline 8 & 298.9 \\
\hline 9 & 344.9 \\
\hline 10 & 344.9 \\
\hline 11 & 369.9 \\
\hline 12 & 370.0 \\
\hline 13 & 404.1 \\
\hline 14 & 404.2 \\
\hline 15 & 439.3 \\
\hline 16 & 526.0 \\
\hline 17 & 526.0 \\
\hline 18 & 555.5 \\
\hline 19 & 555.8 \\
\hline 20 & 616.1 \\
\hline 21 & 616.1 \\
\hline 22 & 702.1 \\
\hline 23 & 765.7 \\
\hline 24 & 765.8 \\
\hline 25 & 786.1 \\
\hline 26 & 802.9 \\
\hline 27 & 839.7 \\
\hline 28 & 839.7 \\
\hline 29 & 999.3 \\
\hline 30 & 1001.1 \\
\hline 31 & 1035.6 \\
\hline 32 & 1036.9 \\
\hline 33 & 1060.2 \\
\hline 34 & 1213.9 \\
\hline 35 & 1213.9 \\
\hline 36 & 1218.7 \\
\hline 37 & 1299.9 \\
\hline 38 & 1301.5 \\
\hline 39 & 1332.2 \\
\hline 40 & 1354.6 \\
\hline 41 & 1372.1 \\
\hline 42 & 1372.1 \\
\hline 43 & 1600.4 \\
\hline 44 & 1600.4 \\
\hline 45 & 1722.5 \\
\hline 46 & 1728.2 \\
\hline 47 & 1836.5 \\
\hline 48 & 1871.3 \\
\hline 49 & 1901.7 \\
\hline 50 & 1903.9 \\
\hline 51 & 1968.6 \\
\hline 52 & 1969.5 \\
\hline 53 & 2018.5 \\
\hline 54 & 2019.2 \\
\hline 55 & 2173.0 \\
\hline 56 & 2297.2 \\
\hline
\end{tabular}

TABLE 3: Continued.

\begin{tabular}{lc}
\hline Mode No. & Freq. $(\mathrm{Hz})$ \\
\hline 57 & 2299.6 \\
58 & 2394.0 \\
59 & 2406.3 \\
60 & 2656.1 \\
61 & 2814.5 \\
62 & 2889.1 \\
63 & 2923.7 \\
64 & 2979.6 \\
65 & 3033.1 \\
66 & 3033.1 \\
67 & 3042.8 \\
68 & 3044.1 \\
69 & 3650.1 \\
70 & 3650.4 \\
72 & 3731.7 \\
\hline
\end{tabular}

However, for the 34th, 35th, and 39th 42nd modes, the relative deviation is almost the same either under fully coupled condition or under partially coupled condition compared to uncoupled condition.

Combining the analysis in Section 3.2, one can observe that these modes, such as the 34th, 35th, and 39th 42nd modes, are particularly dominated by second-stage planetary gear. It clearly indicates that the coupling (interaction) between first-stage planetary gear and second-stage planetary gear has more significant influence on the natural frequencies dominated by second-stage planetary gear compared with the coupling (interaction) between second-stage planetary gear and the output rotor subsystem. Moreover, it can be concluded from Figures 8 and 10(a) that the natural frequencies dominated by first-stage planetary gear are mainly affected by the input rotor subsystem rather than second-stage planetary gear.

As for the torsional vibration modes, Figure 10(b) shows that coupling has more impact on the relative deviation of natural frequency with the order of mode increases. Moreover, Figure 10(b) also illustrates that the natural frequencies dominated by first-stage planetary gear are mainly affected by the input rotor subsystem (see the 36th mode) while the natural frequencies dominated by second-stage planetary gear are mainly affected by first-stage planetary gear (see the 22nd and 33rd modes).

For the two torsional modes of the rigid-body at $0 \mathrm{~Hz}$ in uncoupled condition, one of them jumps to a torsional mode of the two-stage planetary gear subsystem at $263.50 \mathrm{~Hz}$ under partially coupled condition. Furthermore, this mode jumps to a torsional mode for the entire gear rotor system at $56.60 \mathrm{~Hz}$ in fully coupled condition, which is tabulated in Table 4.

Under partially coupled condition, since the interaction between first-stage planetary gear and second-stage planetary gear is considered, the two-stage planetary gear set is considered to be a whole system. For such a system, there is only one rigid-body torsional mode, while the other one turns 


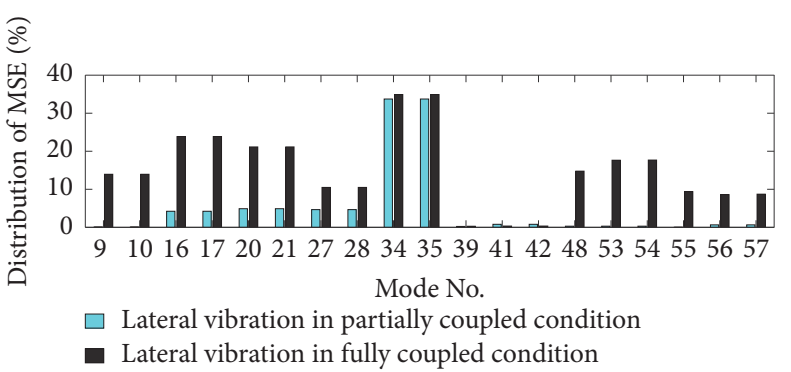

(a)

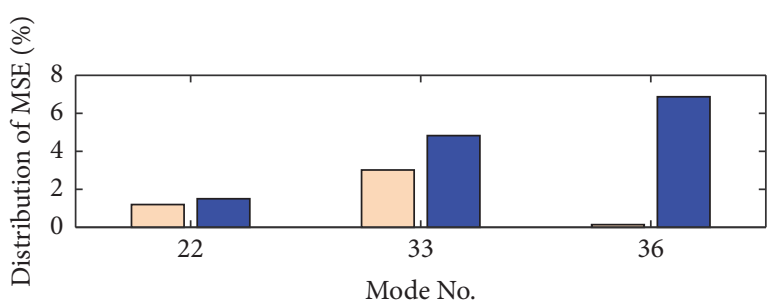

$\square$ Torsional vibration in partially coupled condition

- Torsional vibration in fully coupled condition

(b)

FIGURE 10: Relative deviation of the natural frequencies dominated by the two-stage planetary gear subsystem.

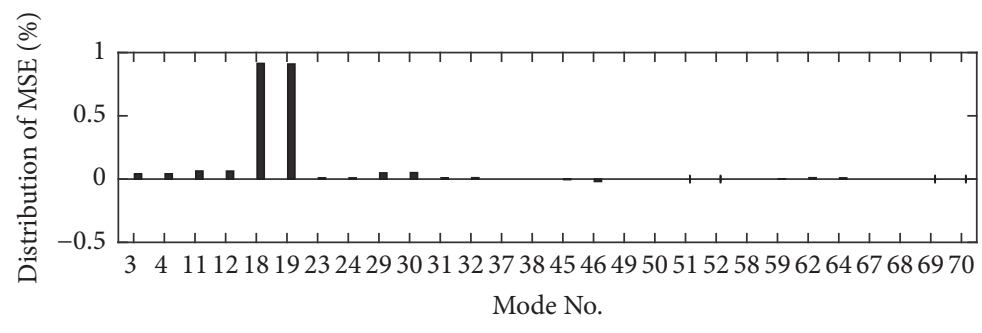

Lateral vibration in partially coupled condition

Lateral vibration in fully coupled condition

(a)

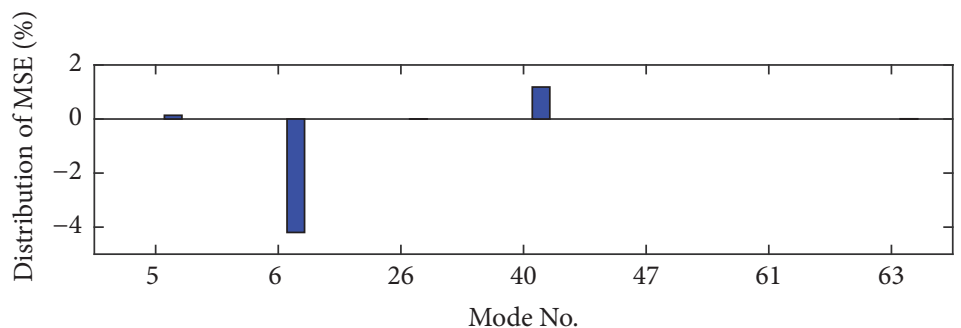

Torsional vibration in partially coupled condition

Torsional vibration in fully coupled condition

(b)

FIGURE 11: Relative deviation of the natural frequencies dominated by the input rotor subsystem.

into a torsional vibration mode of the two-stage planetary gear set at $263.50 \mathrm{~Hz}$. Moreover, the interaction between each two adjacent subsystems is considered in fully coupled condition, which makes the first torsional frequency of the entire gear rotor system further decrease (see the last column of Table 4). One potential cause for this phenomenon is that the whole gear rotor system is a slender flexible rotor system.

\subsubsection{Natural Frequency Dominated by Input Rotor Subsys-} tem. Similar to the previous case, the natural frequencies dominated by the input rotor subsystem under uncoupled, partially coupled, and fully coupled condition are selected, respectively. Moreover, the relative deviation of such natural frequencies is determined in a similar way as that used in the previous case.
TABLE 4: Comparisons of the two zero frequencies under different conditions.

\begin{tabular}{lccc}
\hline Condition & Uncoupled & Partially coupled & Fully coupled \\
\hline \multirow{2}{*}{ Natural frequency } & $0 \mathrm{~Hz}$ & $0 \mathrm{~Hz}$ & $0 \mathrm{~Hz}$ \\
& $0 \mathrm{~Hz}$ & $263.50 \mathrm{~Hz}$ & $56.60 \mathrm{~Hz}$ \\
\hline
\end{tabular}

Excluding the torsional rigid-body mode at $0 \mathrm{~Hz}$, the relative deviation of the natural frequency of the first 72 modes is illustrated in Figure 11. Figure 11(a) clearly indicates that the formulations of partially coupled analysis and fully coupled analysis contribute minimal impact on the lateral frequencies dominated by the input rotor subsystem, with the biggest relative variation ratio about $1 \%$. Figure $11(\mathrm{~b})$ illustrates that, for the torsional frequencies dominated by the input rotor subsystem, the fully coupled analysis has a more 


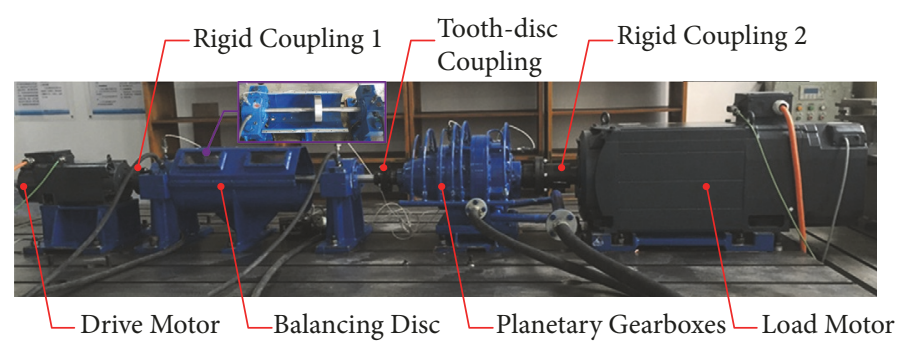

FIgURE 12: Experimental setup.

significant impact on the relative deviation compared to the partially coupled analysis, with a $4.2 \%$ reduction of the 6 th torsional frequency and a $1.2 \%$ increase of the 40 th torsional frequency.

What is more, as shown in Figure 11(b), the relative deviation of the natural frequencies of the 5th, 6th, and 40 th modes is more significant than that of the 26th, 47th, 61st, and 63rd modes. Combining the analysis in Section 3.2, one can observe that though the former modes are dominated by the input rotor subsystem, they are also coupling modes of the input rotor subsystem and first-stage planetary gear. However, the 26th, 47th, 61st, and 63rd modes are all particularly local modes of the input rotor subsystem, which indicates that the restriction effect is faint between the input rotor subsystem and first-stage planetary gear for these modes.

For the torsional rigid-body modal frequency of the input rotor subsystem, it remains constant under partially coupled condition. But it jumps to $56.60 \mathrm{~Hz}$ under fully coupled condition, turning into the first torsional natural frequency.

\section{Experimental Validation}

The laboratory test rig is essentially a two-stage planetary gear rotor system shown in Figure 12. Its main components have been described in Section 2. To verify the lateral-torsional coupling model proposed in this paper which considers the coupling interaction between each two adjacent subsystems, both the torsional and the lateral natural frequencies are determined on the test rig.

Complex systems, like the one considered in this study, are generally characterized by a high density of resonances and mode shapes in a relatively narrow frequency range [13]. In such an instance, it is not easy to correctly associate the numerically computed natural frequencies and mode shapes to the measured ones. To this purpose, the use of Experimental Modal Analysis or other proper strategies may be required [14]. In this present study, Harmonic Response Analysis is performed in order to compare the experimental torsional natural frequencies to the numerical ones, and Experimental Modal Analysis is performed in order to compare the experimental lateral natural frequencies to the numerical ones.

4.1. Torsional Natural Frequency Test and Validation. To gain torsional natural frequencies, the torsional vibration response

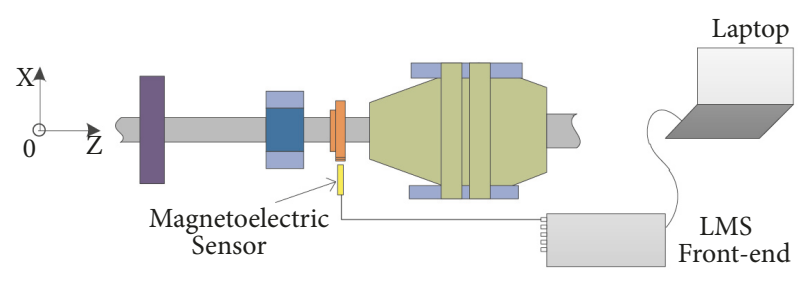

FIGURE 13: Schematic of entire experimental system.

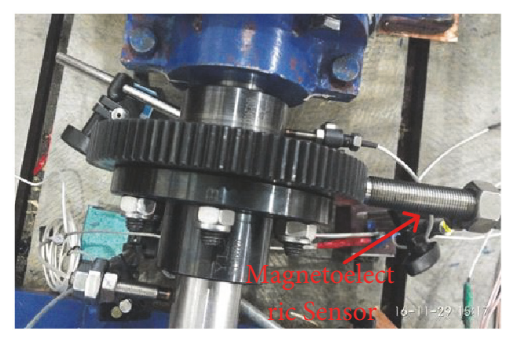

FIGURE 14: Photo of torsional measuring point.

is measured. The schematic of the entire experimental system is shown in Figure 13, and the experimental photo is illustrated in Figure 14. A magnetoelectric sensor is mounted in the vicinity of tooth-disk coupling to collect pulse signals, and its probe is along the axis in a radial direction. Spinning Test is used in this experiment. The vibration response is measured every $50 \mathrm{rpm}$ from $400 \mathrm{rpm}$ to $3400 \mathrm{rpm}$ under idling condition. Vibration signals are processed by a LMS Front-end (LMS SCADAS SCM-05) controlled by software LMS Test.Lab to obtain the torsional frequencies.

Harmonic Response Analysis is performed in order to obtain the experimental torsional natural frequencies. The curve of the first twelve harmonics of the torsional vibration response can be obtained which is shown in Figure 15. Torsional vibration amplitude varying with the frequency is plotted, and resonant peaks appear at the natural frequencies regardless of the harmonic number. Figure 15 shows four natural frequencies of $41.7 \mathrm{~Hz}, 55.8 \mathrm{~Hz}, 145.8 \mathrm{~Hz}$, and $259.6 \mathrm{~Hz}$. However, according to the author's further study, the natural frequency of $41.7 \mathrm{~Hz}$ is associated with a mode of the base of the test rig.

Table 5 compares the torsional natural frequencies identified in spinning test with the numerical prediction. The 


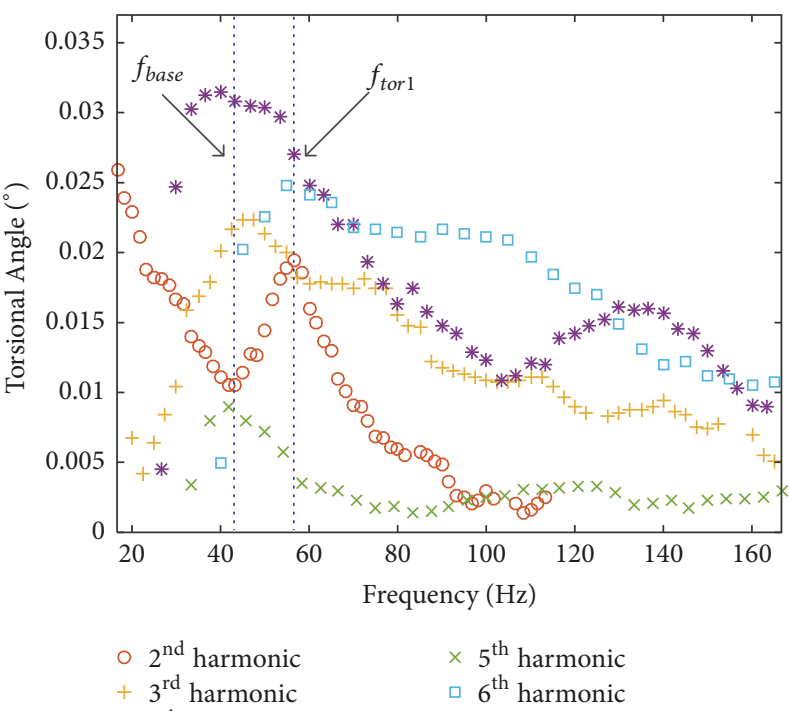

(a)

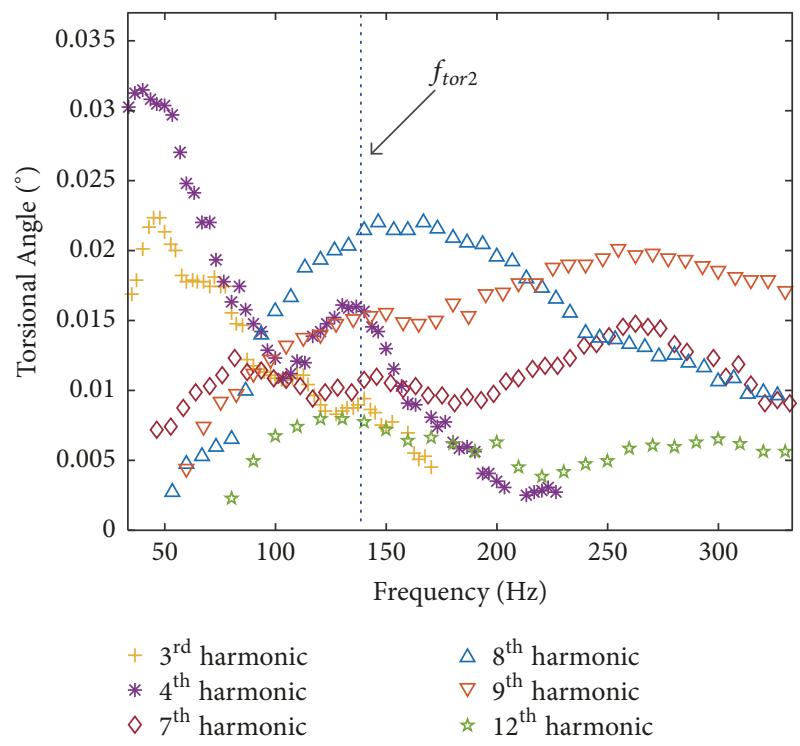

(b)

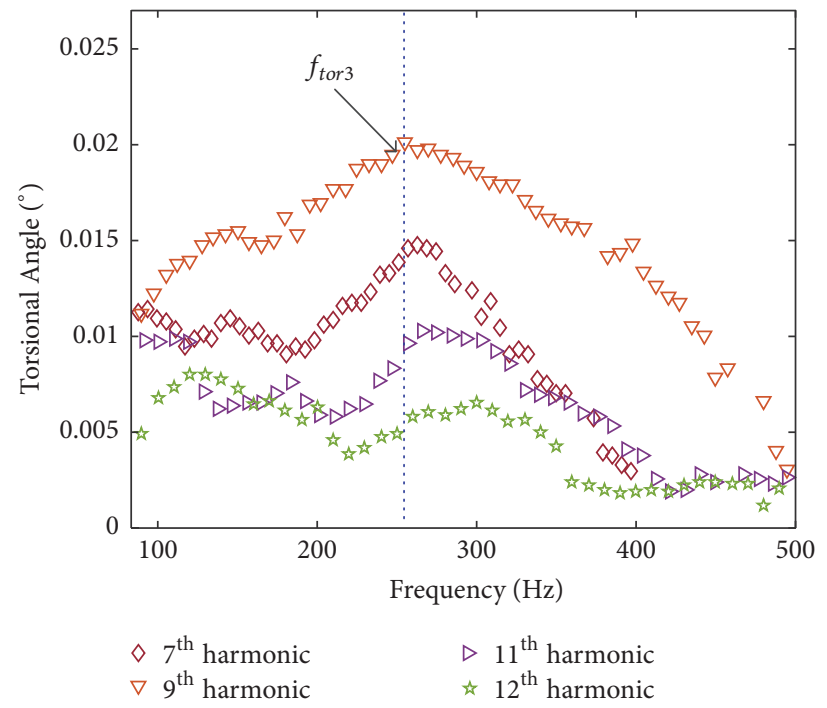

(c)

Figure 15: Torsional vibration response and torsional natural frequency: (a) 2nd through 6th harmonic, (b) 3rd, 4th, 7th, 8th, 9th, and 12th harmonic, and (c) 7th, 9th, 11th, and 12th harmonic.

TABLE 5: Comparison of the torsional natural frequencies between calculation and test.

\begin{tabular}{lccccccc}
\hline Mode No. & $\begin{array}{c}\text { Test } \\
(\mathrm{Hz})\end{array}$ & $\begin{array}{c}\text { Uncoupled } \\
(\mathrm{Hz})\end{array}$ & $\begin{array}{c}\text { Error } \\
(\%)\end{array}$ & $\begin{array}{c}\text { Partial coupled } \\
(\mathrm{Hz})\end{array}$ & $\begin{array}{c}\text { Error } \\
(\%)\end{array}$ & $\begin{array}{c}\text { Full coupled } \\
(\mathrm{Hz})\end{array}$ & $\begin{array}{c}\text { Error } \\
(\%)\end{array}$ \\
\hline 2 & 55.8 & -- & -- & -- & -- & 56.6 & 1.4 \\
5 & 145.8 & 151.0 & 3.6 & 151.0 & 3.6 & 151.2 \\
6 & 259.6 & 259.4 & 0 & 259.4 & 0 & 3.7 \\
\hline
\end{tabular}

results show that the torsional natural frequencies determined by numerical prediction under fully coupled condition correlate with the experimental ones well, and all errors are less than 5\%. Although the errors of the natural frequency of the 2 nd and $3 r d$ torsional modes are less than $5 \%$ under uncoupled and partially coupled conditions, the natural frequency of the first torsional mode is missing under these two conditions.

4.2. Lateral Natural Frequency Test and Validation. To acquire lateral natural frequencies, modal test is carried out. The schematic of the modal test is shown in Figure 16, 
TABLE 6: Comparison of the lateral natural frequencies between calculation and test.

\begin{tabular}{lccccccc}
\hline Mode No. & $\begin{array}{c}\text { Test } \\
(\mathrm{Hz})\end{array}$ & $\begin{array}{c}\text { Uncoupled } \\
(\mathrm{Hz})\end{array}$ & $\begin{array}{c}\text { Error } \\
(\%)\end{array}$ & $\begin{array}{c}\text { Partial coupled } \\
(\mathrm{Hz})\end{array}$ & $\begin{array}{c}\text { Error } \\
(\%)\end{array}$ & $\begin{array}{c}\text { Full coupled } \\
(\mathrm{Hz})\end{array}$ & $\begin{array}{c}\text { Error } \\
(\%)\end{array}$ \\
\hline 3 & 82.9 & 83.7 & 1.0 & 83.7 & 1.0 & 83.7 & 1.0 \\
4 & 83.5 & 83.7 & 0.2 & 83.7 & 0.2 & 83.7 & 0.2 \\
11 & 352.5 & 369.7 & 4.9 & 369.7 & 4.9 & 369.9 & 4.9 \\
12 & 368.7 & 369.8 & 0.3 & 369.8 & 0.3 & 367.0 & 0.5 \\
18 & 454.2 & 550.4 & 21.2 & 550.4 & 21.2 & 555.5 & 22.3 \\
19 & 435.5 & 550.8 & 26.5 & 550.8 & 26.5 & 555.8 & 27.6 \\
23 & 802.7 & 765.6 & 4.6 & 765.6 & 4.6 & 765.7 & 4.6 \\
24 & 794.6 & 765.7 & 3.6 & 765.7 & 3.6 & 765.7 & 3.6 \\
\hline
\end{tabular}

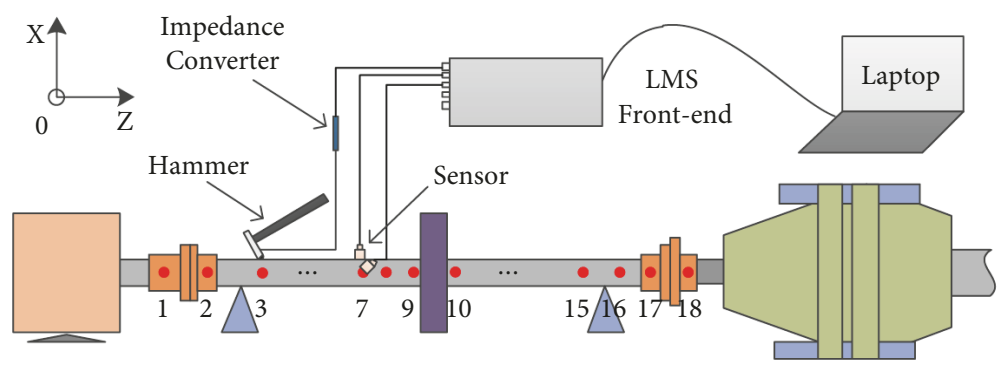

FIGURE 16: Schematic of modal test system.

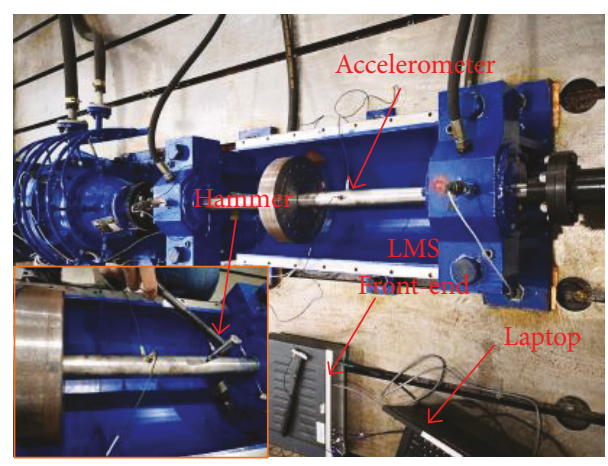

FIgURE 17: Photo of the modal test with test rig.

and the picture of the test rig is illustrated in Figure 17. There are totally 18 measurement points along the input shaft. Such a modal test is implemented by the "roving hammer" approach with two accelerometers (type: Brüel \& Kjær 4526; sensitivity: $9.888 \mathrm{mV} / \mathrm{ms}^{-2}$ and $10.09 \mathrm{mV} / \mathrm{ms}^{-2}$ ) located at point 7. The impact force is imparted through an impact hammer (type: SINOCERA CL-YD-303; sensitivity: $4.06 \mathrm{pC} / \mathrm{N}$ ) with both the nylon and the rubber hammer tip. Signals are sampled by a LMS Front-end (LMS SCADAS SCM-05); such a Front-end is controlled by software LMS Test.Lab in a laptop. The LMS Test.Lab is adopted for signal processing, data management, and parameter estimation purposes.

Experimental Modal Analysis is performed in order to acquire the experimental lateral natural frequencies. Figure 18 shows the $X$ direction sum FRFs and the $Y$ direction sum
FRFs of the input rotor system. As shown in Figure 18(a), only five natural frequencies are found below $1024 \mathrm{~Hz}$ of $X$ direction; however, the similarity of the two corresponding mode shapes of $f_{\text {lat } X 2}$ and $f_{\text {lat } X 2}^{\prime}$ is higher than $70 \%$, which indicates that these two modes are the same mode. As shown in Figure 18(b), six potential natural frequencies are found below $1024 \mathrm{~Hz}$ of $Y$ direction; however, the similarities of mode shapes of $f_{\text {latY2 }}$ and $f_{\text {latY2 }}^{\prime}$ as well as $f_{\text {latY4 }}$ and $f_{\text {latY4 }}^{\prime}$ are both higher than $70 \%$. Thus, the real lateral natural frequencies are $82.9 \mathrm{~Hz}, 352.5 \mathrm{~Hz}, 454.2 \mathrm{~Hz}$, and $802.7 \mathrm{~Hz}$ of $X$ direction and $83.5 \mathrm{~Hz} 368.7 \mathrm{~Hz}, 435.5 \mathrm{~Hz}$, and $794.6 \mathrm{~Hz}$ of $Y$ direction.

Table 6 compares the lateral natural frequencies identified in impact test with the numerical prediction. The results indicate that the numerical lateral natural frequencies under three conditions agree with the experimental ones well, and most errors are less than 5\%, except for the 18th and 19th mode. Furthermore, there is a marginal difference of these eight lateral natural frequencies among these three conditions; in particular this phenomenon confirms the correctness of the conclusions drawn in Section 3.3.2.

\section{Conclusion}

In this paper, the influence of external rotors has been investigated on the vibration characteristics of planetary gears and the lateral-torsional coupling characteristics of the entire system, and a coupled modelling methodology of a two-stage planetary gear rotor system is presented. The proposed fully coupled model offers significant advantages in identifying natural frequencies and vibration mode properties. The conclusions can be summarized as follows: 


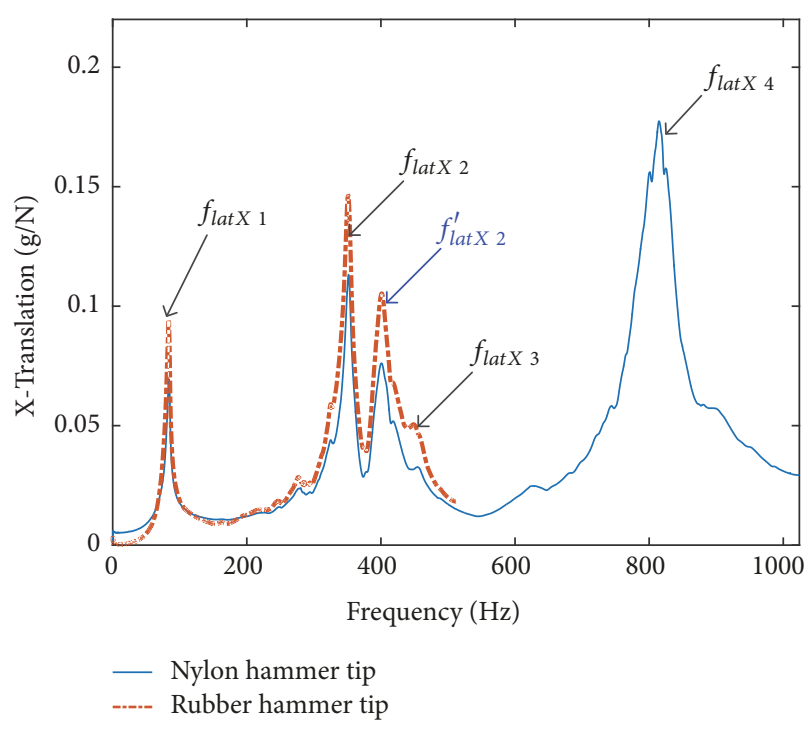

(a)

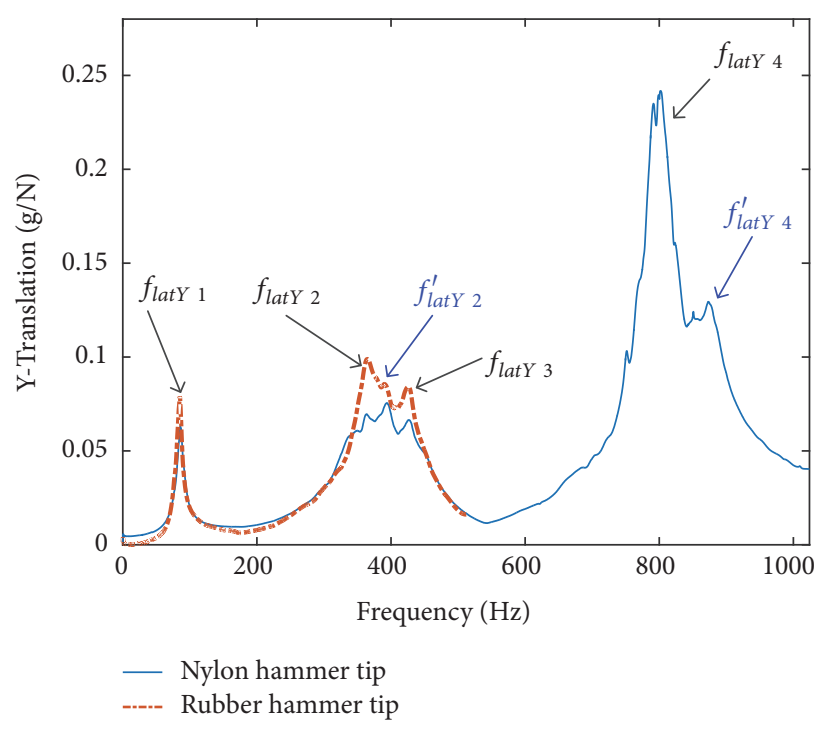

(b)

FIGURE 18: Frequency response of lateral vibration: (a) $X$ direction sum FRFs, and (b) $Y$ direction sum FRFs.

(1) A fully coupled model for the two-stage planetary gear rotor system is presented, where the two-stage planetary gear subsystem is modelled by lumpedparameter method and the external rotor subsystem by finite element method.

(2) The natural frequencies dominated by the two-stage planetary gear subsystem are sensitive to coupling effect. However, the coupling does not obviously affect the natural frequencies dominated by the input rotor subsystem. The first order of the torsional natural frequency is absent unless the fully coupled condition (the interaction between each two adjacent subsystems) is considered.

(3) The coupled modes among multiple subsystems or each two adjacent subsystems mainly appear in the low-mode region; however, in the high-mode region, there are particularly uncoupled and independent modes of the external rotor subsystem. Furthermore, in the high-mode region, there is no coupling effect between the lateral and torsional vibration.

(4) Spinning test and modal test have been done to obtain lateral and torsional natural frequencies, and the experiment data validate the numerical results.

\section{Data Availability}

All the data supporting the conclusions of the study are available on readers' request.

\section{Conflicts of Interest}

The authors declare that there are no conflicts of interest regarding the publication of this paper.

\section{Acknowledgments}

The research work is supported by the Heilongjiang Province Funds for Distinguished Young Scientists (Grant no. JC 201405), China Postdoctoral Science Foundation (Grant no. 2015M581433), and Postdoctoral Science Foundation of Heilongjiang Province (Grant no. LBH-Z15038).

\section{References}

[1] P. Lynwander, Gear Drive Systems: Design and Application, CRC Press, 1983.

[2] A. Kahraman, "Free torsional vibration characteristics of compound planetary gear sets," Mechanism and Machine Theory, vol. 36, no. 8, pp. 953-971, 2001.

[3] A. Kahraman, "Load sharing characteristics of planetary transmissions," Mechanism and Machine Theory, vol. 29, no. 8, pp. 1151-1165, 1994.

[4] J. Lin and R. G. Parker, "Analytical characterization of the unique properties of planetary gear free vibration," Journal of Vibration and Acoustics, vol. 121, no. 3, pp. 316-321, 1999.

[5] C. G. Cooley and R. G. Parker, "The geometry and frequency content of planetary gear single-mode vibration," Mechanical Systems and Signal Processing, vol. 40, no. 1, pp. 91-104, 2013.

[6] J. Lin and R. G. Parker, "Structured vibration characteristics of planetary gears with unequally spaced planets," Journal of Sound and Vibration, vol. 233, no. 5, pp. 921-928, 2000.

[7] Y. Guo and R. G. Parker, "Purely rotational model and vibration modes of compound planetary gears," Mechanism and Machine Theory, vol. 45, no. 3, pp. 365-377, 2010.

[8] L. Zhang, Y. Wang, K. Wu, R. Sheng, and Q. Huang, "Dynamic modeling and vibration characteristics of a two-stage closedform planetary gear train," Mechanism and Machine Theory, vol. 97, pp. 12-28, 2016.

[9] R. August and R. Kasuba, "Torsional vibrations and dynamic loads in a basic planetary gear system," Journal of Vibration, 
Acoustics, Stress, and Reliability in Design, vol. 108, no. 3, pp. 348-353, 1986.

[10] A. Saada and P. Velex, "An extended model for the analysis of the dynamic behavior of planetary trains," Journal of Mechanical Design, vol. 117, pp. 241-247, 1995.

[11] J. Rao S, T. Shiau N, and J. Ghang R, "Theoretical analysis of lateral response due to torsional of geared rotors," Mechanism and Machine Theory, vol. 33, no. 6, pp. 761-783, 1998.

[12] X. H. Liang, M. J. Zuo, and T. H. Patel, "Evaluating time-varying mesh stiffness of a planetary gear set using potential energy method," Journal of Mechanical Engineering Science, vol. 228, no. 3, pp. 535-547, 2014.

[13] T. M. Ericson and R. G. Parker, "Natural frequency clusters in planetary gear vibration," Journal of Vibration and Acoustics, vol. 135, no. 6, Article ID 061002, 2013.

[14] T. M. Ericson and R. G. Parker, "Planetary gear modal vibration experiments and correlation against lumped-parameter and finite element models," Journal of Sound and Vibration, vol. 332, no. 9, pp. 2350-2375, 2013. 


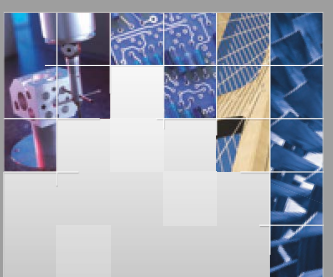

\section{Enfincering}
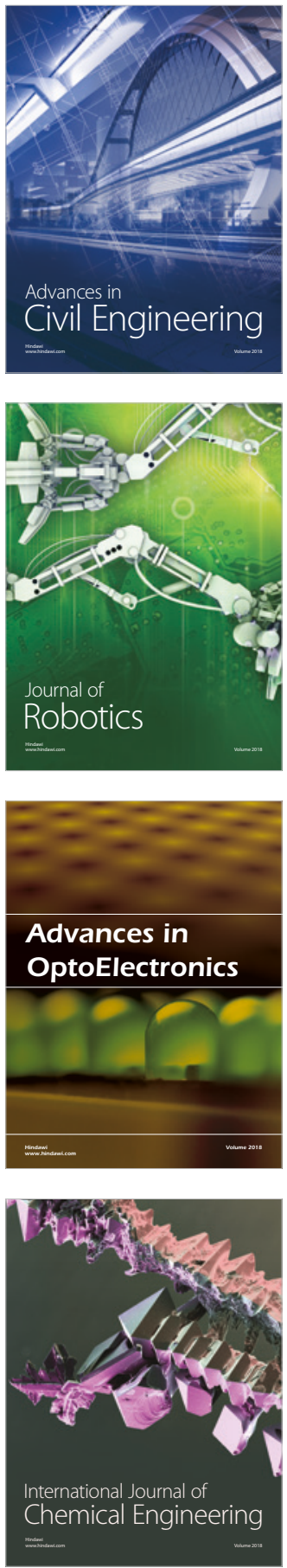

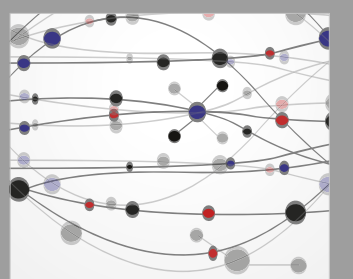

\section{Rotating \\ Machinery}

The Scientific World Journal

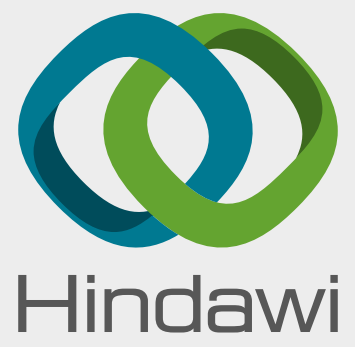

Submit your manuscripts at

www.hindawi.com
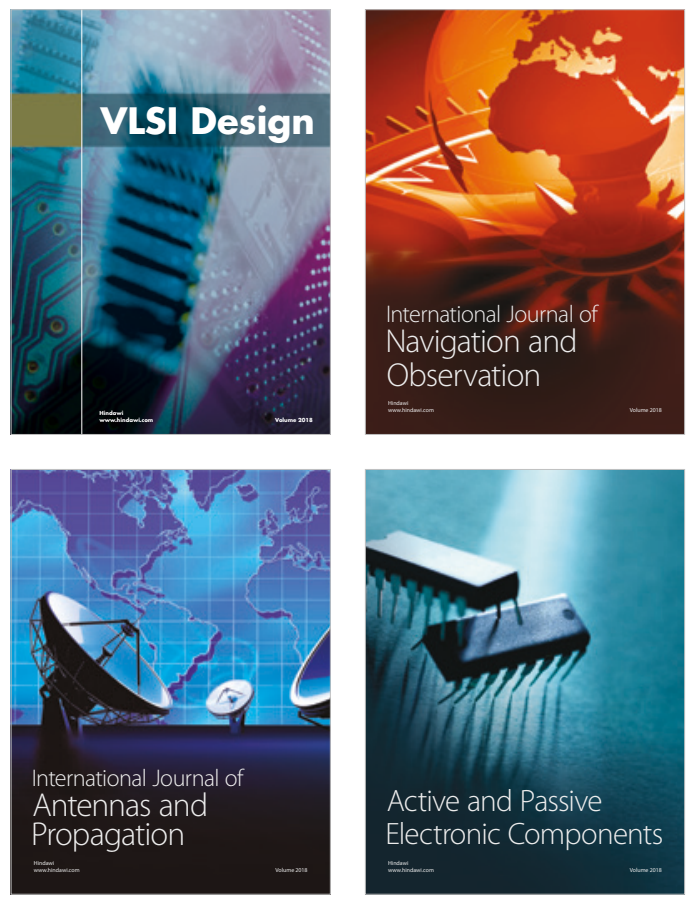
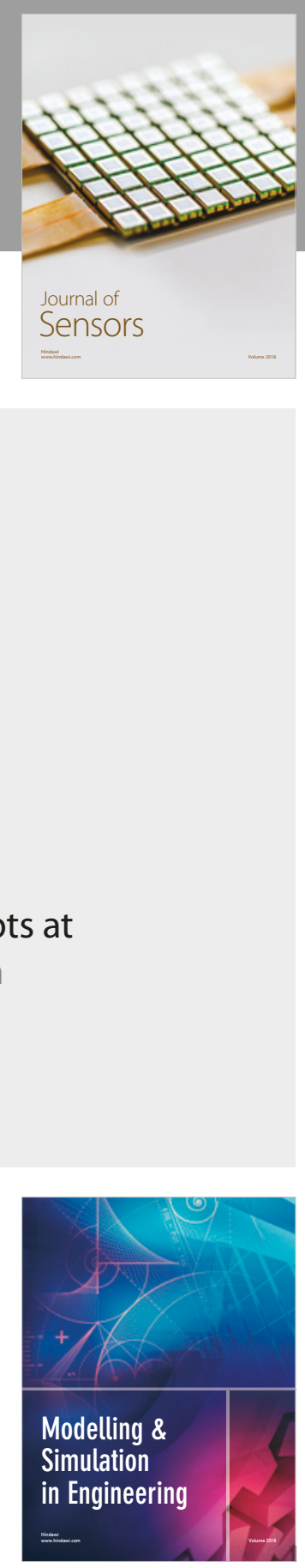

\section{Advances \\ Multimedia}
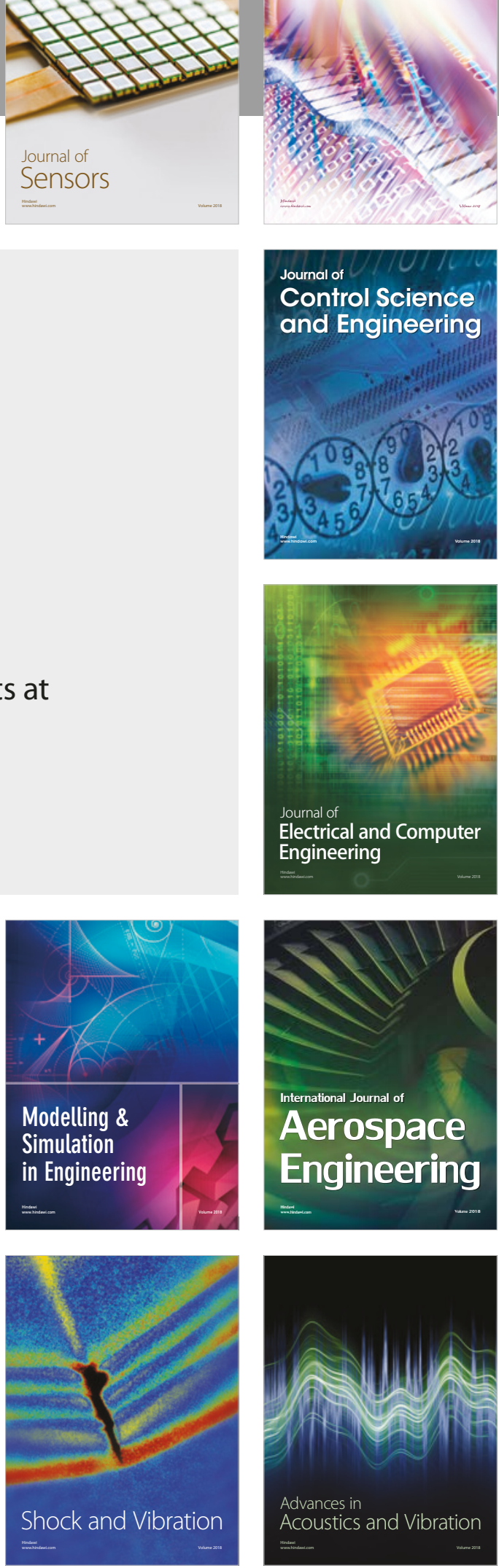